\title{
Subpollen particle release from different species of the invasive allergenic genus Ambrosia: the effect of rainwater composition and wind speed
}

\author{
Sarah Caronni · Rodolfo Gentili (D) C Chiara Montagnani - Sandra Citterio
}

Received: 3 July 2020/ Accepted: 19 July 2021 / Published online: 29 July 2021

(C) The Author(s) 2021

\begin{abstract}
Allergen-containing subpollen particles (SPPs) are micrometric or sub-micrometric particles $(0.12-5 \mu \mathrm{m})$ released from pollen. They are able to reach the lower airways, causing allergenic reactions. SPP release occurs through the pore of intact grains or by rupture of the whole grain. In this paper the results of two laboratory experiments investigating the dynamics of SPP release for three alien species of Ambrosia genus are shown. Rainwater composition and wind speed were considered, by simulating different conditions, in accordance with a fully orthogonal experimental design. The principle response variable was the total percentage of SPPsreleasing pollen grains; also the percentage of intact grains releasing SPPs through the pore and of broken SPPs-releasing grains were considered. Both osmotic and mechanical shock caused the discharge of SPPs but different results were observed. The highest number of releasing grains was recorded in case of acid solution and 20 knots wind speed. Moreover, wind and rainfalls caused SPPs release through different mechanisms. Wind mainly provoked a
\end{abstract}

Supplementary Information The online version contains supplementary material available at https://doi.org/10.1007/ s10453-021-09722-7.

S. Caronni · R. Gentili $(\bowtie) \cdot$ C. Montagnani - S. Citterio Department of Earth and Environmental Sciences, University of Milan-Bicocca, Piazza Della Scienza 1, 20126 Milan, Italy

e-mail: rodolfo.gentili@unimib.it mechanical shock leading to grain rupture, whereas rainfall caused mainly SPPs release through the pore of intact grains. Comparing species, the effect of wind and at least in some cases also that of rainwater appeared to be less relevant for Ambrosia trifida than for Ambrosia psilostachya and Ambrosia artemisiifolia. The obtained results suggest a species-specific response of Ambrosia species to wind speed and rainwater that lead to a different release of SPPs and then to a species-specific impact on allergy according to the characteristics of their growth environment.

Keywords Subpollen particles - Airborne pollen . Pollinosis $\cdot$ Ambrosia $\cdot$ Pollen rupture $\cdot$ Asthma

\section{Introduction}

Pollen allergens are extensively known to induce pollinosis and allergic inflammation throughout both the upper and lower respiratory tracts (D'Amato, 2002; Sagara et al., 2009). Nevertheless, how pollencarried allergens contribute to the development of inflammation in the lower airways has remained a puzzle for a long time as pollen grains are considered too large to reach the lower respiratory tracts (Bacsi et al., 2006; Driessen \& Quanjer, 1991; Pazmandi et al., 2012). Furthermore, during development, pollen components including allergenic proteins are 
encapsulated in the cytoplasm or embedded in the pollen wall (intine and exine layers); therefore, unless these components are released from the pollen grains, they cannot react with the immune system, causing allergic reactions (D'Amato et al., 2007).

In natural conditions, mature pollen undergoes a process of dehydration before being released from anthers and then it becomes rehydrated by stigma secretion, in order to germinate and fertilize female gametes. This process usually occurs without causing cell damage or spilling cell contents (Firon et al., 2012). On the contrary, the contact of pollen grains with rainwater or under high humidity conditions causes the rapid absorption of water and the consequent release of SPPs, allergenic proteins, enzymes and bioactive lipid mediators in the form of micrometric or sub-micrometric particles $(0.12-5 \mu \mathrm{m}$; Grote et al., 2000; Behrendt \& Becker, 2001; Bacsi et al., 2006). According to Smiljanic et al. (2016), the SPP fraction of pollen grains contains the highest proportion (more than 90\%) of the allergome of allergenic species. SPPs release can occur both by rupture of the whole grain and through germination pores or tubules (Grote et al., 2001).

Bartková-Šcevková (2003) observed that the occurrence of pollen grains in the atmosphere markedly relates to meteorological factors. Visez et al. (2015) have recently demonstrated that SPPs are released even when the mechanical shock of grains against a solid surface occurs. In addition to osmotic shock caused by rainwater, indeed, also the wind-induced mechanical rupture of pollen grains seems to be involved in the discharge of pollen cytoplasmic contents.

Once released, SPPs can be transported for long distances (e.g., Grewling et al., 2016), thus explaining the recurrent cases of exposure to allergens recorded in the absence of identifiable airborne pollen grains (Barnes et al., 2000). Holding also functional NAD(P)H oxidase, SPPs possess antigenic and redox properties and, due to the small size, they are able to reach even the lower airways, causing epidemics of asthma, usually known as thunderstorm asthma (Boldogh et al., 2005; Motta et al., 2006; Ritsick \& Lambeth, 2005). Such events, indeed, have been frequently associated with summer thunderstorms, characterized by significant changes in weather, increasing rainfalls and winds (Knox, 1993; Wark et al., 2002). In 2017, thunderstorm-related asthma attacks interested thousands of patients and caused a few fatal cases in Melbourne, Australia (D'Amato et al., 2017).

SPPs release has been reported for species of very different genera (e.g., Schappi et al., 1999; Taylor et al., 2004; De Linares et al., 2010) and has been studied in different allergenic species during thunderstorms (e.g., Taylor \& Jonsson, 2004; D' Amato et al., 2007; D'Amato et al., 2017). Nevertheless, very scarce information about the main environmental factors affecting pollen grain rupture and SPPs release is still available in the literature for several extremely allergenic species (Siriwattanakul et al., 2019).

Ambrosia genus, in particular, groups wind-pollinated herbaceous plants, almost ubiquitous in North America, which has spread rapidly across Europe (Oswalt \& Marshall, 2008), where it causes allergic disorders in more than 36 million people each year (Bordas-Le Floch et al., 2015; Montagnani et al., 2017). Ambrosia artemisiifolia L. is the most representative species of the genus and the major cause of seasonal respiratory allergies in different regions of Europe since the 1990s (D'Amato et al., 1992; Rasmussen et al., 2017). It produces massive quantities of pollen (D'Amato et al., 2007); a single specimen may generate millions of highly allergenic pollen grains of 18-22 $\mu \mathrm{m}$ (Bordas-Le Floch et al., 2015; Bouley et al., 2015; D'Amato et al., 2007; Gadermaier et al., 2014).

Several papers on A. artemisiifolia allergenicity are present in the literature (e.g., Ghiani et al., 2012; Pazmandi et al., 2012; Gentili et al. 2018) while little information on its congeneric species is available. In temperate regions of Europe, such as Italy and Croatia, it is known that the allergenic pathologies caused by $A$. artemisiifolia emerge between the end of August and the end of September, due to the seasonal release of its pollen in the atmosphere (Müller-Germann et al., 2017; Peternel et al., 2006). Anyway, a poor correlation between pollen grain counts and related allergic symptoms on atopic subjects has been observed in many areas (Bacsi et al., 2006; Siriwattanakul et al., 2019), suggesting that in those cases SPPs released in the air represent the major allergen source. Furthermore, it cannot be excluded that a fraction of SPPs carrying allergens could originate from other Ambrosia species.

In this paper, the effect of rainwater composition and wind speed on the dynamic and mechanism of SPP 
release from A. artemisiifolia, A. psilostachya and A. trifida was investigated. To the purpose, collected pollen was exposed to gentle, moderate and fresh breeze and to laboratory prepared solutions simulating near-neutral, acid and saline rain.

\section{Materials and methods}

\subsection{Plant materials}

Five plants for each of the three target species $(A$. artemisiifolia, A. psilostachya and A. trifida) were collected in the field from random areas across Lombardy (Northern Italy) and transplanted into a commercial soil (composition: $47.8 \%$ organic carbon of biological origin; $1.3 \%$ organic nitrogen; $82.4 \%$ organic matter; $\mathrm{pH}$ 6-7). Plants were grown under controlled conditions in a growth chamber, with constant temperature $\left(25{ }^{\circ} \mathrm{C}\right)$, humidity $(65 \%)$ and day/night cycles $(10 \mathrm{~h}$ of darkness and $14 \mathrm{~h}$ of light; with a Photosynthetic Photon Flux Density of $150 \mu \mathrm{mol} \mathrm{m} \mathrm{m}^{-2} \mathrm{~s}^{-1}$ ). Mature pollen grains, naturally released from anthers, were collected in transparent collectors, by covering the inflorescences with a modified ARACON system (Lommen et al., 2017). Grains were separated from the other particles by sieving and inspected under a light microscope to ensure 95\% purity. Pollen samples were then stored in dark boxes with silica gel at room temperature until analysis. The storage time was the same (about 1 month) for all the three species to avoid any effect due to difference in pollen aging.

\subsection{Pollen treatments}

\subsubsection{Rainwater-simulating aqueous solutions}

Pollen grains were exposed to the following three aqueous solutions that were prepared accordingly to Chester et al. (2000) and Neves et al. (2009), to simulate the following three different environmental conditions of rainwater:

(A) near-neutral rain, which was simulated by using Milliq water with $\mathrm{pH} \sim 6.5$;

(B) acid rain, which was simulated with Milliq water acidified to $\mathrm{pH} \sim 3.0$ with $\mathrm{HNO}_{3}(20 \mathrm{mg} / \mathrm{ml})$ and $\mathrm{H}_{2} \mathrm{SO}_{4}(20 \mathrm{mg} / \mathrm{ml})$;
(C) saline rain, which was simulated by using a 0.9\% Sodium Chloride solution, $\mathrm{pH} \sim 5.5$. in Milliq water.

Operatively, $0.2 \mathrm{mg}$ of pollen containing about 1500 grains were deposited on a slide, covered with $20 \mu \mathrm{l}$ of one of the three solutions and observed under a light microscope; the percentage of SPPs-releasing pollen grains was counted upon hydration and 1 and $24 \mathrm{~h}$ after it (Ghiani et al., 2012). Four different slides were prepared for each considered species, treatment and time to avoid dependence of data $(n=4)$. Finally, the total percentage of releasing pollen grains was calculated for each replicate, summarizing the count of broken SPPs-releasing grains (BRGs, recognizable at the light microscope for the presence of a visible rupture of the pollen wall, Fig. 1) and the count of intact grains releasing SPPs through the pore (PRGs, recognizable for the presence of "bubbles" from the pores; Fig. 1). The total number of counted pollen grains was about 5000-6000 for each species and for each time of analysis.

\subsubsection{Wind speeds}

In order to simulate the effect of wind at $10(18 \mathrm{~km} / \mathrm{h}$; gentle breeze in the Beaufort scale), $15(27 \mathrm{~km} / \mathrm{h}$; moderate breeze in the Beaufort scale) and 20 knots ( $37 \mathrm{~km} / \mathrm{h}$; fresh breeze in the Beaufort scale), $2 \mathrm{mg}$ of pollen was inserted into a vacuum flask and compressed air (6 atm) was shot inside it for one minute at the three above-mentioned speeds (SM1). The speed was determined by inserting into the flask a small digital anemometer prior to start the experiment. The three considered wind speeds were defined taking into account the environmental conditions of the distribution areas of the species. Specifically, A. psilostachya is typical of coastal areas, where wind blows at least at $40 \mathrm{~km} / \mathrm{h}$ especially in summer when the plant development is maximum. Instead, A. artemisiifolia and A. trifida are typical of flat lands where summer wind speed is usually less than $30 \mathrm{~km} / \mathrm{h}$, especially in urbanized areas (less than $20 \mathrm{~km} / \mathrm{h}$ ). After exposition to wind, $0.2 \mathrm{mg}$ of the manipulated pollen were deposited on a slide and immediately observed under a light microscope, counting the number of SPPsreleasing pollen grains (Ghiani et al., 2012). Almost all the $2 \mathrm{mg}$ of pollen present in the vacuum were observed. ( $\mathrm{n}=10$; pollen was re-weighted after shooting it and weight differences were always less 


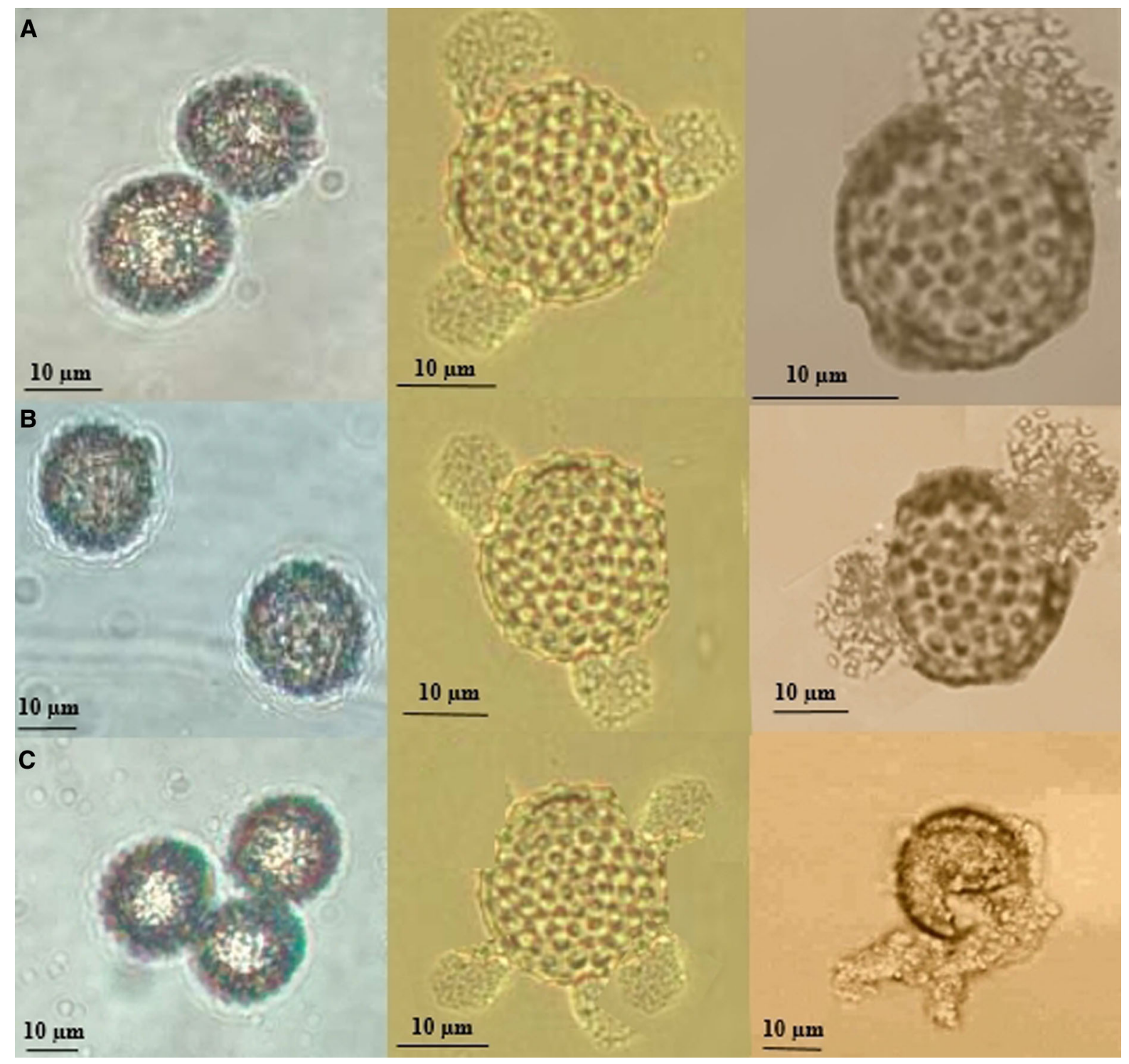

Fig. 1 Non-SPP releasing, releasing through the pore and broken pollen grain, respectively, of (a) A. artemisiifolia, (b) A. trifida and (c) A. psilostachya

than $0.05 \mathrm{mg}$.) Three replicates were considered for each wind condition and the percentage of the total SPPs-releasing grains, broken grains (BRGs) and intact grains releasing SPPs through the pore (PRGs) was calculated for each (Fig. 1).

\subsection{Statistical analysis}

The software GMAV5 (University of Sydney, Australia) was used for statistical analysis. In particular, different ANOVAs were applied to the data when normality and homogeneity (Cochran test) of variance were satisfied. Furthermore, where the ANOVAs provided significant results, Student-Newman-Keuls (SNK) a posteriori test was also run for post hoc comparison of means (Underwood, 1997). When significant, the SNK test was performed on the interactions among the considered factors.

The effect of the three aqueous solutions was tested by means of a four-way ANOVA. The following fixed factors were considered: "time," three levels (immediately after hydration $v s 1 \mathrm{~h}$ after hydration $v s 24 \mathrm{~h}$ 
after hydration), "treatment," three levels (A vs B vs C), "species," three levels (A. artemisiifolia vs A. psilostachya vs A. trifida) and "releasing mode, two levels (intact grains releasing SPPs through the pore $v s$ broken SPPs-releasing grains). To test the effect of wind speed, instead, an orthogonal three-way ANOVA was performed considering "species" as a fix factor with three levels (A. artemisiifolia vs A. psilostachya vs A. trifida), "wind speed " as a fix factor with three levels (gentle breeze vs moderate breeze $v s$ fresh breeze) and "releasing mode " as a fix factor with two levels (intact grains releasing SPPs through the pore $v s$ broken SPPs-releasing grains). Also in this case, Student-Newman-Keuls (SNK) tests were used for a post-hoc comparison of means for significant results (Underwood, 1997).

\section{Results}

\subsection{Effect of the rainwater-simulating aqueous solutions}

Overall, significant differences in the number of SPPsreleasing pollen grains were recorded among species in relation to both aqueous solutions and sampling times (SM2). Figure 2 shows the total percentage of releasing grains over time for each species after exposure to the different solutions. In general, immediately after hydration, few grains (around or less than $1 \%$ ) released SPPs. At this time, no difference due to the solution type was observed for A. artemisiifolia and for A. psilostachya, whereas a significant lower effect of the acid solution in inducing SPP releasing was observed for A. trifida. (Fig. 2; SM2). Interestingly, over time, a different effect of solutions was observed both within each species and among the three species. Specifically, all the species showed a consistent increase in the percentage of SPPs-releasing grains after $1 \mathrm{~h}$ of hydration with the acid solution that further increased after $24 \mathrm{~h}$ (Fig. 2; SM 2). A. psilostachya, in particular, showed the highest increase, from about $1 \%$ upon hydration to about $7 \%$ after $24 \mathrm{~h}$, whereas A. artemisiifolia and A. trifida from about $1 \%$ to about $3 \%$. About the effect of the near-neutral solution, it induced a limited increase in the number of SPPs-releasing grains during the first hour only for A. artemisiifolia (from 1.2 to 1.9\%) and A. trifida (from 0.9 to 1.3 ). The percentage remained
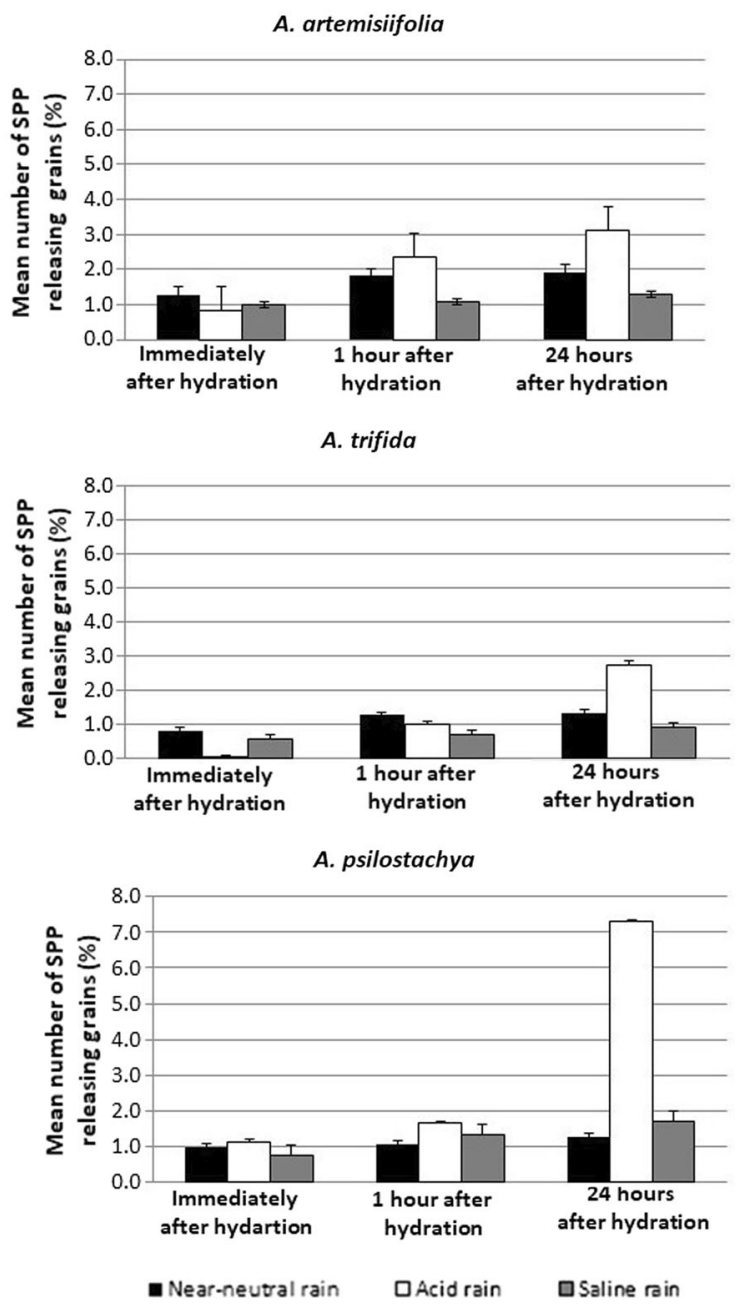

Fig. 2 Percentage of SPPs-releasing grains for the three considered species in relation to the hydration treatment for each considered time. Each value represents the mean ( \pm ES) of the four independent counts performed

about $1 \%$ in A. psilostachya. Furthermore, in such conditions, no significant increases for all the species were observed $24 \mathrm{~h}$ after hydration. Finally, the saline solution showed the lowest or at least equal effect than near-neutral solution in both $A$. artemisiifolia and $A$. trifida, whereas it induced a higher release than the near-neutral solution in A. psilostachya over time (saline rainwater: $1.7 \%$ vs near-neutral solution with about $1 \%$ after $24 \mathrm{~h}$ ).

The percentage of broken SPPs-releasing grains (BRGs) and of intact grains releasing SPPs through the germination pore (PRGs), out of total releasing grains, are reported in Fig. 3. PRGs were generally more 


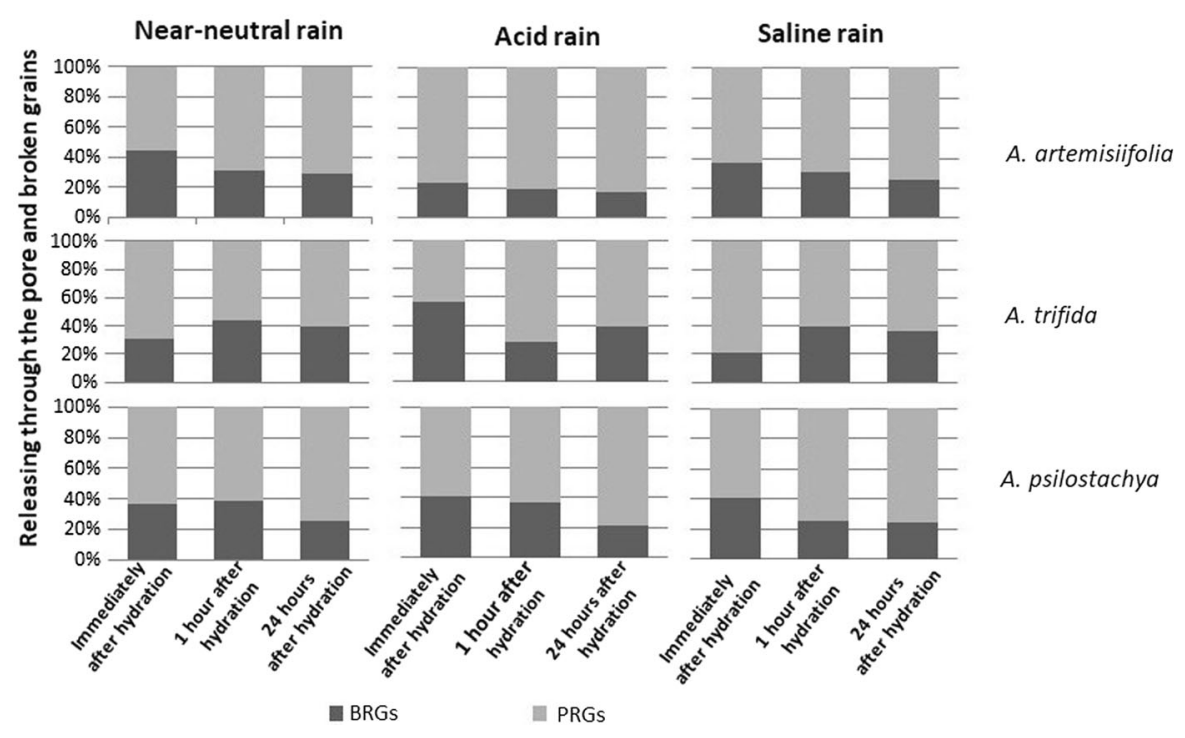

Fig. 3 Ratio between the number of broken SPPs-releasing grains (BRGs) and the number of intact grains releasing SPPs through the pore (PRGs) for each species, time and hydration

abundant than BRGs (SM 2) and no germination was observed during the experiment. Even if not statistically significant, some remarkable differences among species, times and treatments were observed. For $A$. artemisiifolia and A. psilostachya the highest relative percentage of BRGs, although always less than PRGs, was recorded immediately after hydration and decreased over time. Specifically, upon hydration with near-neutral, acid and saline solutions, $A$. artemisiifolia BRGs were $41 \%, 21 \%$ and $38 \%$ out of total releasing grains, respectively. These percentage reached the values of $24 \%, 19 \%, 21 \%$, respectively, after 24 h. Similarly, A. psilostachya BRG percentage were $39 \%, 40 \%$ and $40 \%$ of total releasing grains immediately after hydration and reached values of $22 \%, 20 \%$ and $21 \%$, respectively, after 24 h (Fig. 3; Differently, A. trifida BRG percentage decreased over time only with the acid solution: Initially their relative percentage was higher (58\%) than that of PRGs (42\%) and decreased up to $39 \%$ after $24 \mathrm{~h}$. On the contrary, upon hydration with near-neutral and saline solutions the initial relative percentage of A. trifida BRGs (30\% and $20 \%$, respectively) were lower than those observed $1 \mathrm{~h}$ after the exposure $(41 \%$ and $39 \%$, respectively) (Fig. 3; SM 2). treatment considered. Each value represents the mean of the four independent counts performed

\subsection{Effect of wind speed}

Significant differences in the percentage of SPPsreleasing grains were recorded among species in relation to wind speed (gentle breeze, moderate breeze and fresh breeze, SM 3). Figure 3 shows the number of SPPs-releasing grains for each species at the three speeds. Overall, the highest release percentage were observed for A. psilostachya when the wind speed was higher $(\sim 25 \%)$. The other two species displayed significantly lower release percentage also in windy conditions ( $\sim 20 \%$ and $15 \%$ for A. artemisiifolia and A. trifida, respectively, with fresh breeze) (Fig. 4; SM 3). No pollen germination was observed.

Out of the total SPPs-releasing grains, the percentage of BRGs was always significantly higher than that of PRGs ( $\sim 80 \%$ and $20 \%$, respectively), independently of the wind speed, for all the three considered species (Fig. 4; SM 3). In detail, the BRG percentage appeared to be a bit lower for A. artemisiifolia especially in case of gentle breeze $(67 \%)$. The highest values were instead observed for A psilostachya, independently from the treatment (almost $>$ of 90\%) and for A. trifida, especially in the case of fresh breeze $(93 \%)$. 

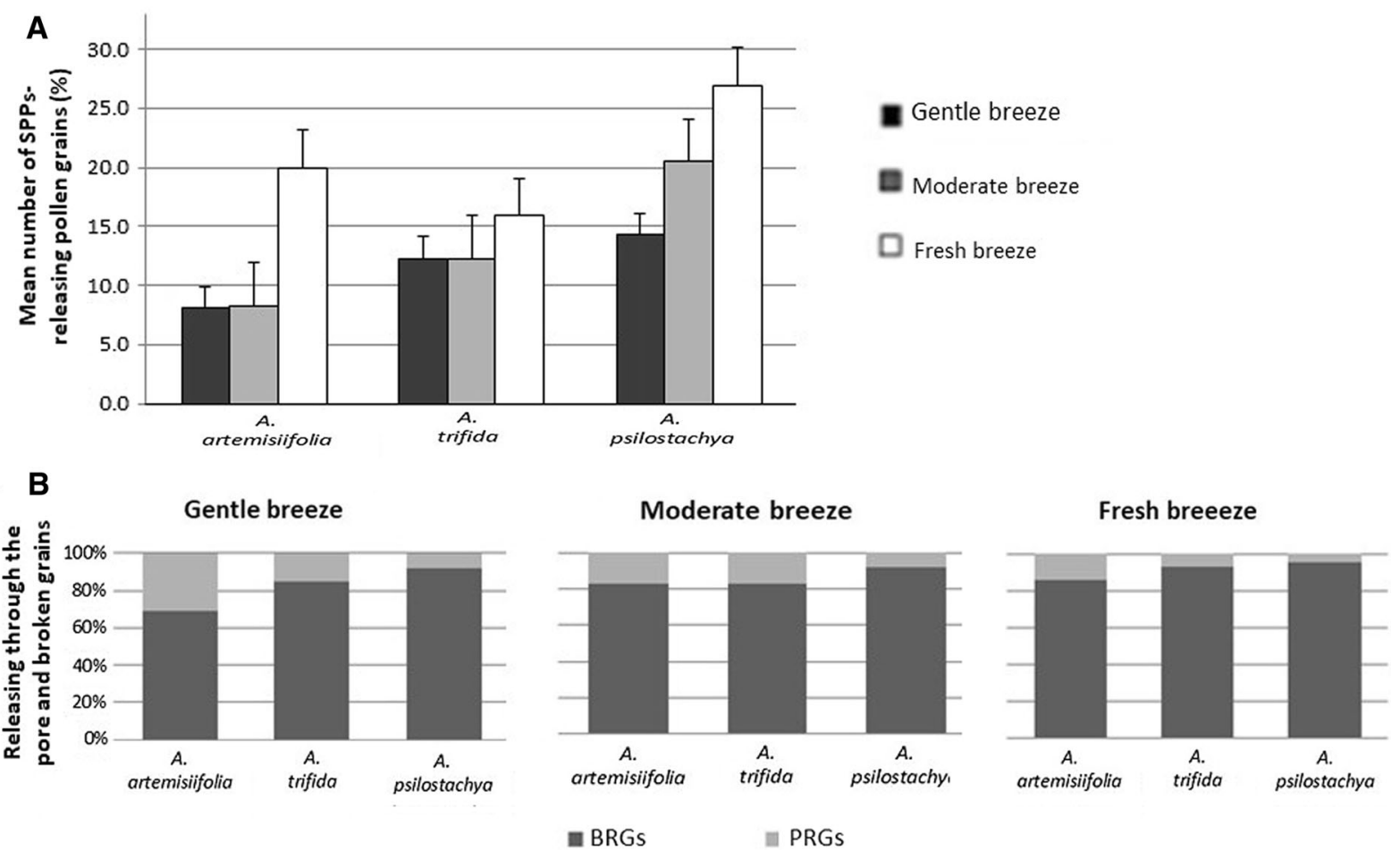

Fig. 4 a Percentage of SPP releasing grains after exposure to the considered wind treatments for each of the three species. Each value represents the mean $( \pm \mathrm{ES})$ of the ten independent counts overall performed. $\mathbf{b}$ Ratio between the number of broken

SPPs-releasing grains (BRGs) and the number of intact grains releasing SPPs through the pore (PRGs) for each species and wind treatment considered. Each value represents the mean of the four independent counts performed

\section{Discussion}

The results of this study provide interesting information on the dynamics of subpollen particles release in different environmental conditions for the three species of the invasive genus Ambrosia, which are currently considered as one of the most significant causes of allergenic disease worldwide (Ziska et al., 2011). In particular, analyzing the effect of wind and rainfall, the two main environmental parameters that seem to play a key role in SPP release (Visez et al., 2015), different results were overall obtained, depending on both the species and the tested conditions, in terms of wind speed, rainfall $\mathrm{pH}$ and exposure time.

First, we observed that rainfalls and wind caused SPP release through different mechanisms. In the case of wind, the release appears to be mainly the result of the mechanical shock generated by wind on pollen grains that causes their rupture, as already observed for other wind-dispersed pollens (Emmerson et al., 2021). Indeed, the recorded significant increase in BRGs in

parallel with the increase in wind speed provides evidence that, in such conditions, SPP release is mainly the result of grain rupture due to pollen kinetic energy and to the mechanical stress produced by the continuous and strong impacts occurring when wind wildly shifts grains. Accordingly to Visez et al. (2015) the pollen grains hit trees, walls, cars and all other kinds of hard surfaces releasing SPPs, which being particularly light micrometric or sub-micrometric particles, are immediately captured by air currents, becoming themselves airborne.

Hydration of pollen in case of rainfalls, instead, seems to act mainly through a different mechanism involving SPP release through the pore of intact grains. Although grain rupture happened upon hydration in our experiment, SPP release through the pore of intact grains generally seems to represent the main release mode, especially over time. These results are in accordance with those of Harrington and Metzger (1963), who described for the first time a significant release of cytoplasmic material through the pore of $A$. 
artemisiifolia pollen grains some hours after hydration. Anyway, in agreement with authors, who consider the grain breakdown the cause of SPP release after hydration (De Linares et al., 2010; Knox et al., 1997; Siriwattanakul et al., 2019; Suphioglu et al., 1992), we also observed the rupture of some pollen grains after aqueous solution exposure. In fact, upon hydration, the water penetrates rapidly through the germinative pore of the more exposed grains, hydrating them in a few seconds causing an osmotic shock (Danti et al., 2011; Grote et al., 2001). However, after this initial extreme condition, that causes the sudden rupture of some grains, water starts diffusing gradually into the other grains, increasing slowly their internal pressure and consequently favoring the discharge of cytoplasmic material trough the pore of intact grains (Flagan, 2008).

Additional factors influencing the mechanisms of SPP release were the rainwater composition and the considered Ambrosia species. With regard to rainwater composition, for all the three investigated species, the highest number of releasing grains was recorded in acid solution conditions, especially after $24 \mathrm{~h}$ of exposure. These data suggest that acid solutions can have notable effects not only on the germination of pollen grains of certain species (e.g., Munzuroglu et al., 2003) but also on their SPP release. Presumably, this effect is related to the significant changes in the cytoplasmic composition of grains and in their structure, caused by the remarkably low water $\mathrm{pH}$ (3.5), influencing the release of SPPs through the pore and/or the grain resistance to turgor pressure (Grote et al., 2001; Steer \& Steer, 1989). With regard to the species, instead, a significantly higher number of SPPs-releasing grains were observed for A. artemisiifolia and for A. psilostachya than for A. trifida immediately after hydration with the acid solution. These data suggest that, during the first phases of the hydration process, each species displays a peculiar release pattern, as already observed by Siriwattanakul et al. (2019) for other species. Significant differences among species were also noticed analyzing the effect of wind speed. As for hydration, the effect of fresh wind appeared to be less relevant for the release of A. trifida SPPs in comparison with the other two species and, especially to A. psilostachya. Thus, according to observations on other genus (Franssen et al. 2001), the response of pollen grains to both mechanical and osmotic changes induced by environmental conditions seems to be species-specific. As no significant size differences occurred among the pollen grains of the three species, the recorded differences can be, at least partially, explained considering the main elements playing a role in grain rupture and particle release trough the pore. The regulation of pollen grains water balance, from which grain rupture depends, is strictly related to the exine thickness, elasticity and composition (Duhoux, 1982). According to Heslop-Harrison (1979), exines are among the most diverse structures of the world, also for chemical composition (Southworth 1973), and the differences in their peculiar features can remarkably influence the resistance to rupture of grains (Duhoux, 1982). Moreover, as already mentioned, the differences in the chemical composition of the cytoplasm seem to play a role in determining the magnitude of SPP release trough the pore of intact grains for a defined species (Grote et al., 2001).

According to Robbins et al. (1979), A. trifida grains appeared to be characterized by a coarser exine, presumably thicker and more resistant to rupture than that of the other two species. This characteristic likely explains the lower release observed for this species when exposed to acid rainwater and fresh breeze. Interestingly, A. trifida appeared to be quite different from the other two species also in terms of proteome (Barton and Schomacker 2007). The different behavior of A. trifida is also confirmed by the ratio BRGs/ PRGs. In this species, such ratio increased during exposure with near-neutral and saline solutions, whereas it decreased in $A$. artemisiifolia and $A$. psilostachya in the same conditions. This situation suggests that for A. trifida, the exposure time contributes more than the hydration process itself to grain rupture (Taylor et al., 2007).

Moreover, considering the specific response of the three ragweed species to rainwater composition and wind speed along with the peculiar characteristics of their growth habitats, we can suppose a different impact on allergy for each of them. Ambrosia psilostachya is typical of coastal areas (Rich, 1994; Mandrioli 1998; Weeda, 2010; Del Vecchio et al., 2015; Fried et al., 2015; Montagnani et al., 2017), where marine aerosols produce saline (Chester et al., 2000) and the frequency of wind events is usually quite high. As in our experiment breeze induced a consistent SPPs release, we can suppose that the synergy of wind and saline rainfall may induce a high 
release of SPPs in the atmosphere, with a consequent impact on ragweed allergy in such type of environments. A further greater effect may be recorded in human impacted coastal areas where rainfalls are also often acid, due to atmospheric pollution (Menz \& Seip, 2004; Puckett, 1982). However, because A. psilostachya usually has a more restricted range than A. artemisiifolia, although a high SPPs release can happen in costal environments, the overall impact on allergy might be also negligible.

Moreover, in the future it is likely that the percentage of SPPs-releasing pollen grains will decrease further reducing the impact of A. psilostachya allergy. Indeed, it has expected a plant adaptation to the specific costal environmental conditions that favor sturdier pollen, more resistant to saline rainwater and strong wind, able to maintain germinating function. However, it should be taken into account that climate is quickly changing and the possible increase in wind speed and salt concentration in the atmosphere could affect the integrity of pollen grains that will have adapted.

Ambrosia artemisiifolia and Ambrosia trifida are instead typical of lowland areas, both urbanized or not (Montagnani et al., 2017), where the incidence of wind is usually almost negligible respect to coastal areas. In this case, the main cause of the release of SPPs is represented by osmotic shock, as observed in previous studies for other species with similar distribution ranges (e.g., Visez et al., 2015). In this environment, due to the low percentage of SPPs-releasing grains, it is likely that the impact of these species on allergy is negligible in the absence of wind. The only exception may be represented by urban environment where rainfalls are acid and $A$. artemisiifolia is highly invasive. In this condition, a quite high SPPs release is expected on the basis of our experiment that can contribute to pollinosis outbreaks.

Summarizing, the allergenic impact of A. artemisiifolia, A. psilostachya and A. trifida can differ significantly among areas with different environmental conditions, as already described for other genus such as Cupressus (Charpin et al., 2005) and can change with climate change.

In conclusion, the obtained results suggest that different patterns of SPP release can occur also among species of the same genus and that, beyond their physiological characteristics, they are strictly related to environmental conditions. Therefore, gaining information about subpollen particle release patterns of the most allergenic species in their typical habitats is crucial to set prevention programs and to acquire detailed pictures of their impact, taking into account also the main environmental parameters influencing their SPP release patterns.

Acknowledgements We thank Benedetta Ciceri and Giulia Piazza for the precious help during laboratory analyses and data analysis.

Funding Open access funding provided by Università degli Studi di Milano - Bicocca within the CRUI-CARE Agreement.

Open Access This article is licensed under a Creative Commons Attribution 4.0 International License, which permits use, sharing, adaptation, distribution and reproduction in any medium or format, as long as you give appropriate credit to the original author(s) and the source, provide a link to the Creative Commons licence, and indicate if changes were made. The images or other third party material in this article are included in the article's Creative Commons licence, unless indicated otherwise in a credit line to the material. If material is not included in the article's Creative Commons licence and your intended use is not permitted by statutory regulation or exceeds the permitted use, you will need to obtain permission directly from the copyright holder. To view a copy of this licence, visit http://creativecommons.org/licenses/by/4.0/.

\section{References}

Bacsi, A., Choudhury, B. K., Dharajiya, N., Sur, S., \& Boldogh, I. (2006). Subpollen particles: carriers of allergenic proteins and oxidases. The Journal of Allergy and Clinical Immunology, 118, 844-850.

Barnes, C., Schreiber, K., Pacheco, F., Landuyt, J., Hu, F., \& Portnoy, J. (2000). Comparison of outdoor allergenic particles and allergen levels. Annals of Allergy, Asthma \& Immunology, 84, 47-54.

Bartková-Šcevková, J. (2003). The Influence of Temperature, Relative Humidity and Rainfall on the Occurrence of Pollen Allergens (Betula; Poaceae; Ambrosia artemisiifolia $</ \mathrm{i}>$ ) in the Atmosphere of Bratislava (Slovakia). International Journal of Biometeorology, 48, 1-5.

Barton, J. S., \& Schomacker, R. (2017). Comparative protein profiles of the Ambrosia plants. Biochimica Et Biophysica Acta, 1865, 633-639.

Behrendt, H., \& Becker, W. M. (2001). Localization, release and bioavailability of pollen allergens: the influence of environmental factors. Current Opinion in Immunology, 13, 709-715.

Boldogh, I., Bacsi, A., Choudhury, B. K., Dharajiya, N., Alam, R., Hazra, T. K., et al. (2005). ROS generate by a pollen NADPH oxidase provide a signal that augments antigeninduced allergic airway inflammation. The Journal of Clinical Investigation, 115, 2169-2179.

Bordas-Le Floch, V., Groeme, R., Chabre, H., Baron-Bodo, V., Nony, E., Mascarell, L., et al. (2015). New insights into 
ragweed pollen allergens. Current Allergy and Asthma Reports, 15, 1-7.

Bouley, J., Groeme, R., Le Mignon, M., Jain, K., Chabre, H., Bordas-Le Floch, V., et al. (2015). Identification of the cysteine protease Amb a 11 as a novel major allergen from short ragweed. The Journal of Allergy and Clinical Immunology, 136, 1055-1054.

Celenk, S. (2019). Detection of reactive allergens in long-distance transported pollen grains: evidence from Ambrosia. Atmospheric Environment, 209, 212-219.

Charpin, D., Calleja, M., Lahoz, C., Pichot, C., \& Waisel, Y. (2005). Allergy to cypress pollen. Allergy, 60, 293-301.

Chester, R., Nimmo, M., Fones, G. R., Keyse, S., \& Zhang, J. (2000). The solubility of $\mathrm{Pb}$ in coastal marine rainwaters: $\mathrm{PH}-\mathrm{dependent} \mathrm{relationships.} \mathrm{Atmospheric} \mathrm{Environment,}$ 34, 3875-3887.

D'Amato, G. (2002). Environmental urban factors (air pollution and allergens) and the rising trends in allergenic respiratory diseases. Allergy, 57, 30-33.

D’Amato, G., Dal Bo, S., \& Bonini, S. (1992). Pollen-related allergy in Italy. Annals of Allergy, 68, 433-437.

D’Amato, G., Cecchi, L., Bonini, S., Nunes, C., Annesi-Maesano, I., Behrendt, H., et al. (2007). Allergenic pollen and pollen allergy in Europe. Allergy Eur J Allergy Clin Immunol, 62, 976-990.

D’Amato, G., Annesi Maesano, I. A., Molino, A., Vitale, C., \& D'Amato, M. (2017). Thunderstorm-related asthma attacks. The Journal of Allergy and Clinical Immunology, 139, 1786-1787.

Danti, R., Della Rocca, G., Calamassi, R., Mori, B., \& Mariotti Lippi, M. (2011). Insights into a hydration regulating system in Cupressus pollen grains. Annals of Botany, 108, 299-306.

De Linares, C., Díaz de la Guardia, C., Nieto Lugilde, D., \& Alba, F. (2010). Airborne study of grass allergen (lol p 1) in different-sized particles. International Archives of Allergy and Immunology, 152, 49-57.

Del Vecchio, S., Pizzo, L., \& Buffa, G. (2015). The response of plant community diversity to alien invasion: evidence from a sand dune time series. Biodiversity and Conservation, 24, 371-392.

Driessen, M. N., \& Quanjer, P. H. (1991). Pollen deposition in intrathoracic airways. European Respiratory Journal, 4, 359-363.

Duhoux, E. (1982). Mechanism of exine rupture in hydrated taxoid type of pollen. Grana, 21, 1-7.

Emmerson, K. M., Silver, J. D., Thatcher, M., Wain, A., Jones, P. J., Dowdy, A., et al. (2021). Atmospheric modelling of grass pollen rupturing mechanisms for thunderstorm asthma prediction. PloS one, 16, 0249488.

Firon, N., Nepi, M., \& Pacin, E. (2012). Water status and associated processes mark critical stages in pollen development and functioning. Annals of Botany, 109, 1201-1214.

Flagan, R. C. (2008). When Asthma Strikes. Engineering \& Science, 71, 26-33.

Fried, G., Belaud, A., \& Chauvel, B. (2015). Ecology and impact of an emerging invasive species in France: Western ragweed (Ambrosia psilostachya DC.). Rev. Ecol. Terre Vie, $70,53-67$.
Gadermaier, G., Hauser, M., \& Ferreira, F. (2014). Allergens of weed pollen: an overview on recombinant and natural molecules. Methods, 66, 55-66.

Ghiani, A., Aina, R., Asero, R., Bellotto, E., \& Citterio, S. (2012). Ragweed pollen collected along high-traffic roads shows a higher allergenicity than pollen sampled in vegetated areas. Allergy, 67, 887-894.

Grewling, Ł, Bogawski, P., Jenerowicz, D., Czarnecka-Operacz, M., Šikoparija, B., Skjøth, C. A., \& Smith, M. (2016). Mesoscale atmospheric transport of ragweed pollen allergens from infected to uninfected areas. International Journal of Biometeorology, 60, 1493-1500.

Grote, M., Vrtala, S., Niederberger, V., Valenta, R., \& Reichelt, R. (2000). Expulsion of allergen-containing materials from hydrated rye grass (Lolium perenne) pollen revealed by using immunogold field emission scanning and transmission electron microscopy. Journal of Allergy and Clinical Immunology, 105, 1140-1145.

Grote, M., Vrtala, S., Niederberger, V., Wiermann, R., Valenta, R., \& Reichelt, R. (2001). Release of allergen-bearing cytoplasm from hydrated pollen: a mechanism common to a variety of grass (Poaceae) species revealed by electron microscopy. The Journal of Allergy and Clinical Immunology, 108, 109-115.

Harrington, J. B., \& Metzger, K. (1963). Ragweed pollen density. American Journal of Botany, 50, 532-539.

Heslop-Harrison, J. (1979). An interpretation of the hydrodynamics of pollen. American Journal of Botany, 66, 737-743.

Knox, R. B. (1993). Grass pollen, thunderstorms and asthma. Clinical and Experimental Allergy, 23, 354-359.

Knox, R. B., Suphioglu, C., Taylor, P., Desai, R., Watson, H. C., Peng, J. L., \& Bursill, L. A. (1997). Major grass pollen allergen Lol p 1 binds to diesel axhaust particles: Implications for asthma and air pollution. Clinical and Experimental Allergy, 27, 246-251.

Mandrioli, P., Di Cecco, M., \& Andina, G. (1998). Ragweed pollen: the aeroallergen is spreading in Italy. Aerobiologia, $14,13-20$.

Menz, F. C., \& Seip, H. M. (2004). Acid rain in Europe and the United States: an update. Environmental Science \& Policy, 7, 253-265.

Mikhailov, E. F., Ivanova, O. A., Nebosko, E. Y., Vlasenko, S. S., \& Ryshkevich, T. I. (2019). Subpollen particles as atmospheric cloud condensation nuclei. Izvestiya, Atmospheric and Oceanic Physics, 55, 357-364.

Montagnani, C., Gentili, R., Smith, M., Guarino, M. F., \& Citterio, S. (2017). The worldwide spread, success, and impact of ragweed (Ambrosia spp.). Critical Reviews in Plant Sciences, 36, 139-178.

Motta, A. C., Marliere, M., Peltre, G., Sterenberg, P. A., \& Lacroix, G. (2006). Traffic-related air pollutants induce the release of allergen-containing cytoplasmic granules from grass pollen. International Archives of Allergy and Immunology, 139, 294-298.

Müller-Germann, I., Pickersgill, D. A., Paulsen, H., Alberternst, B., Pöschl, U., Fröhlich-Nowoisky, J., \& Després, V. R. (2017). Allergenic Asteraceae in Air Particulate Matter: Quantitative DNA Analysis of Mugwort and Ragweed ».Aerobiologia, 1, 14. 
Munzuroglu, O., Obek, E., \& Geckil, H. (2003). Effects of simulated acid rain on the pollen germination and pollen tube growth of apple (Malus sylvestris Miller cv. Golden). Acta Biologica Hungarica, 54, 95-103.

Neves, N. R., Oliva, M. A., da Cruz Centeno, D., Costa, A. C., Ribas, R. F., \& Pereira, E. G. (2009). Photosynthesis and oxidative stress in the restinga plant species Eugenia uniflora L. exposed to simulated acid rain and iron ore dust deposition: potential use in environmental risk assessment. Science of the Total Environment, 407, 3740-3745.

Oswalt, M. L., \& Marshall, G. D. (2008). Ragweed as an example of worldwide allergen expansion. Allergy, Asthma and Clinical Immunology, 4, 130-135.

Pazmandi, K., Kumar, B. V., Szabo, K., Boldogh, I., Szoor, A., Vereb, G., et al. (2012). Ragweed subpollen particles of respirable size activate human dendritic cells. PLoS ONE, 7, e52085.

Peternel, R., Čulig, J., Hrga, I., \& Hercog, P. (2006). Airborne ragweed (Ambrosia artemisiifolia L.) pollen concentrations in Croatia, 2002-2004. Aerobiologia, 22, 161-168.

Puckett, L. J. (1982). Acid rain, air pollution, and tree growth in southeastern NewYork. Journal of Environmental Quality, 11, 376-381.

Rasmussen, K., Thyrring, J., Muscarella, R., Borchsenius, F. (2017). Climate-change-induced range shifts of three allergenic ragweeds (Ambrosia L.) in Europe and their potential impact on human health. PeerJ. 5. e3104

Rich, T. C. G. (1994). Ragweeds (Ambrosia L.) in Britain. Grana, 33, 38-43.

Ritsick, D. R., \& Lambeth, J. D. (2005). Spring brings breezes, wheezes, and pollen oxidases. The Journal of Clinical Investigation, 115, 2067-2069.

Robbins, R. R., Dickinson, D. B., \& Rhodes, A. M. (1979). Morphometric analysis of pollen from four species of Ambrosia (Compositae). American Journal of Botany, 66, 538-545.

Sagara, H., Yukawa, T., Kashima, R., Okada, T., \& Fukuda, T. (2009). Effects of pranlukast hydrate on airway hyperresponsiveness in non-asthmatic patients with Japanese cedar pollinosis. Allergology International, 58, 277-287.

Schappi, G. F., Taylor, P. E., Staff, I. A., Rolland, J. M., \& Suphioglu, C. (1999). Immunologic significance of respirable atmospheric starch granules containing major birch allergen Bet v 1. Allergy, 54, 478-483.
Siriwattanakul, U., Piboonpocanun, S., \& Songnuan, W. (2019). Rapid pollen rupture and release of pollen cytoplasmic granules upon hydration of allergenic grass and weed species commonly found in subtropical regions. Aerobiologia, 35, 719-730.

Smiljanic, K., Apostolovic, D., Trifunovic, S., Ognjenovic, J., Perusko, M., Mihajlovic, L., Burazer, L., van Hage, M., \& Cirkovic Velickovic, T. (2017). Sub-pollen particles are rich carriers of major short ragweed allergens and NADH dehydrogenases: quantitative proteomic and allergomic study. Clinical \& Experimental Allergy, 47, 815-828.

Steer, M. W., \& Steer, J. M. (1989). Tansley review no. 16. Pollen Tube Tip Growth New Phytologist, 111, 323-358.

Suphioglu, C., Singh, M., Taylor, P. R. B., Bellomo, R., Holmes, P., \& Puy, R. (1992). Machanism of grass-pollen-induced asthma. The Lancet, 339, 569-572.

Taylor, P. E., \& Jonsson, H. (2004). Thunderstorm Asthma. Curr. Allergy Asthma Rep., 4, 409-413.

Taylor, P. E., Flagan, R. C., Miguel, A. G., Valenta, R., \& Glovsky, M. M. (2004). Birch pollen rupture and the release of aerosols of respirable allergens. Clinical and Experimental Allergy, 34, 1591-1596.

Taylor, C. M., Parker, D. J., \& Harris, P. P. (2007). An observational case study of mesoscale atmospheric circulations induced by soil moisture. Geophys: Res. Lett. https://doi. org/10.1029/2007GL030572

Underwood, A. J. (1997). Experiments in ecology: their logical design and interpretation using analysis of variance. Cambridge University Press.

Visez, N., Chassard, G., Azarkan, N., Naas, O., Sénéchal, H., Sutra, J. P., et al. (2015). Wind-induced mechanical rupture of birch pollen: Potential implications for allergen dispersal. Journal of Aerosol Science, 89, 77-84.

Wark, P. A., Simpson, J., Hensley, M. J., \& Gibson, P. G. (2002). Airway inflammation in thunderstorm asthma. Clinical and Experimental Allergy, 32, 1750-1756.

Weeda, E. J. (2010). The role of archaeophytes and neophytes in the Dutch coastal dunes. Journal of Coastal Conservation, 14, 75-79.

Ziska, L., Knowlton, K., Rogers, C., Dalan, D., Tierney, N., Elder, M. A., et al. (2011). Recent warming by latitude associated with increased length of ragweed pollen season in central North America. Proceedings of the National Academy of Sciences of the United States of America, 108, 4248-4251. 